\title{
Toxicidade letal e subletal do nim sobre o pulgão-verde e seu predador Eriopis connexa
}

\author{
Madelaine Venzon(1), Maria da Consolação Rosado(2), Angelo Pallini(2), Amanda Fialho( ${ }^{(2)}$ e Célia de Jesus Pereira( ${ }^{(2)}$ \\ (1)Empresa de Pesquisa Agropecuária de Minas Gerais, Centro Tecnológico da Zona da Mata, Vila Gianetti, no 46, CEP 36570-000 Viçosa, MG. \\ E-mail: venzon@epamig.ufv.br (2)Universidade Federal de Viçosa, Dep. de Biologia Animal, Av. P.H. Rolfs, s/no, Campus UFV, CEP $36570-000$ \\ Viçosa, MG. E-mail: mcrosado@insecta.ufv.br, pallini@ufv.br, fialho@insecta.ufv.br, celia@insecta.ufv.br
}

\begin{abstract}
Resumo - O objetivo deste trabalho foi avaliar, em laboratório, os efeitos do extrato de semente de nim sobre uma praga da pimenteira, o pulgão-verde Myzus persicae (Sulzer), e seu predador Eriopis connexa (Germar). Folhas de pimenteira foram imersas em solução aquosa de extrato de semente de nim ( $1 \%$ de azadiractina) a $0,5 \%, 1 \%$, em acefato $\left(0,75 \mathrm{~g} \mathrm{~L}^{-1}\right)$ e em água. Fêmeas do pulgão foram transferidas para essas folhas e, após seis dias, avaliouse a população final. Larvas de quarto ínstar do predador foram colocadas em plantas de pimenteira infestadas com pulgões e pulverizadas com solução aquosa de nim a 0,25 e, $0,5 \%$, em acefato $\left(0,75 \mathrm{~g} \mathrm{~L}^{-1}\right)$ e em água. Após 48 horas, as larvas foram transferidas para tubos de plástico e alimentadas com pulgões. A mortalidade larval, a viabilidade pupal e a emergência de adultos foram avaliadas. A população de pulgões foi significativamente menor em folhas tratadas com nim e com acefato do que nas tratadas com água. A mortalidade de larvas do predador foi maior em plantas tratadas com acefato do que com nim. No entanto, somente $9,1 \mathrm{e} 10 \%$ das larvas em plantas tratadas com nim a $0,25 \%$ e a $0,5 \%$, respectivamente, formaram pupas e não houve emergência de adultos. Apesar do potencial do nim em reduzir a população de $M$. persicae, o produto apresenta efeitos nocivos a E. connexa.
\end{abstract}

Termos para indexação: Azadirachta indica, Myzus persicae, Coccinellidae, Capsicum frutescens.

\section{Lethal and sublethal toxicity of neem on green peach aphid and on its predator Eriopis connexa}

\begin{abstract}
The aim of this work was to assess, in laboratory, the effects of neem seed extract on chilli pepper pest, the green peach aphid Myzus persicae (Sulzer) and on its predator Eriopis connexa (Germar). Chilli pepper leaves were treated with an aqueous solution of neem seed extract ( $1 \%$ of azadiractin) at concentrations of 0.5 and $1.0 \%$, using acephate $\left(0.75 \mathrm{~g} \mathrm{~L}^{-1}\right)$ and water. Aphid females were transferred to treated leaves and after six days the aphid population was checked. Fourth-instar larvae of E. connexa were placed on pepper seedlings infested with aphids and sprayed with an aqueous solution of neem at 0.25 and $0.5 \%$, using acephate $\left(0.75 \mathrm{~g} \mathrm{~L}^{-1}\right)$ and water. After 48 hours, larvae were transferred to plastic tubes and fed aphids. Larval mortality, pupal viability and adult emergence were evaluated. Aphid population was significantly lower on leaves treated with neem and acephate than on water treated plants. Mortality of E. connexa larvae was higher on plants treated with acephate than on neem treated plants. However, only 9.1 and $10 \%$ of larvae on plants treated with neem at 0.25 and $0.5 \%$, respectively, reached the pupal phase and there was no adult emergence. In spite of the potential of neem to reduce $M$. persicae population, the product shows deleterious effects on E. connexa.
\end{abstract}

Index terms: Azadirachta indica, Myzus persicae, Coccinellidae, Capsicum frutescens.

\section{Introdução}

O pulgão Myzus persicae (Sulzer) (Hemiptera: Aphididae) é uma das principais espécies de afídeos que causam danos às culturas. Além de danos diretos, resultantes da sucção contínua da seiva das plantas, essa espécie pode atuar também como vetor de várias viroses (Blackman \& Eastop, 1984; Minks \& Harrewijn, 1987).
A espécie $M$. persicae é considerada uma das pragas-chave da pimenteira (Capsicum spp.) e de outras culturas. Quando atacadas, as folhas da pimenteira apresentam-se enroladas e encarquilhadas, ao passo que seus brotos tornam-se curvos e achatados e os ramos terminais podem secar e morrer. Ataques intensos dessa espécie-praga nessa cultura causam queda significativa na produção. No entanto, os prejuízos mais significativos 
são decorrentes de danos indiretos causados pela transmissão do vírus-do-mosaico-do-pimentão (França et al., 1984; Pinto et al., 1999; Quiroz et al., 2005).

O controle químico é o método tradicionalmente utilizado no monitoramento de pulgões na cultura da pimenta (Pinto et al., 1999). Porém, com o aumento dos problemas relacionados ao uso exclusivo e constante de defensivos químicos e com a crescente exigência por alimentos livres de agrotóxicos, é necessária a utilização de métodos alternativos ao controle químico para o manejo de pragas. Além disso, existe apenas um produto registrado para o controle de pulgões na cultura da pimenteira, aumentando-se assim a probabilidade do desenvolvimento de resistência por essas pragas. Outro fator a ser considerado é que essa cultura é utilizada principalmente na agricultura familiar, em que a necessidade de métodos alternativos e de baixo custo é ainda maior.

Os extratos de plantas com potencial inseticida têm sido utilizados em sistemas de produção em que não é permitido o uso de agrotóxicos, como na produção orgânica, e em alguns sistemas familiares, devido à facilidade de aquisição e ao custo relativamente baixo, quando comparado aos inseticidas convencionais. Uma das espécies de planta mais difundidas no controle de pragas é a Azadirachta indica A. Juss, conhecida como nim. A azadiractina, encontrada principalmente nas sementes, e em menor quantidade na casca e nas folhas do nim, é o principal composto responsável pelos efeitos tóxicos aos insetos (Schmutterer, 1990; Mordue \& Nisbet, 2000). Os efeitos da azadiractina sobre insetos incluem repelência, deterrência alimentar, interrupção do crescimento, interferência na metamorfose, esterilidade e anormalidades anatômicas (Schmutterer, 1990; Mordue \& Nisbet, 2000; Martinez \& Emden, 2001).

Produtos derivados do nim têm vantagem de ser praticamente não tóxicos ao homem e ser rapidamente degradados no solo e nas plantas (Isman, 2006). Com relação aos inimigos naturais, os efeitos são variáveis, mas, de maneira geral, são menos suscetíveis ao nim do que os insetos fitófagos, devido, principalmente, ao modo de ação do nim (Schmutterer, 1997; Akol et al., 2002).

O objetivo deste trabalho foi avaliar, em laboratório, os efeitos do extrato de semente de nim sobre uma praga da pimenteira, o pulgão-verde $M$. persicae e seu inimigo natural Eriopis connexa (Germar) (Coleoptera: Coccinellidae).

\section{Material e Métodos}

Fêmeas de $M$. persicae foram obtidas em plantas de pimenta-malagueta (Capsicum frutescens L.) cultivadas em vasos mantidos em casa de vegetação da Empresa de Pesquisa Agropecuária de Minas Gerais (Epamig), Centro Tecnológico da Zona da Mata (CTZM), em Viçosa, MG. O extrato de semente de nim utilizado nos testes foi o produto comercial NeemAzal T/S que contém $10 \mathrm{~g} \mathrm{~L}^{-1}$ do ingrediente ativo azadiractina.

No laboratório, folhas de pimenteira, retiradas de plantas não infestadas mantidas em casa de vegetação, foram imersas por cinco segundos em solução aquosa de extrato de semente de nim a $0,5 \%\left(0,05 \mathrm{~g} \mathrm{~L}^{-1}\right.$ de i.a. $)$ ou a $1 \%\left(0,1 \mathrm{~g} \mathrm{~L}^{-1}\right.$ de i.a.), ou em solução aquosa de acefato $\left(0,75 \mathrm{~g} \mathrm{~L}^{-1}\right.$ de i.a.) (Orthene $\left.750 \mathrm{BR}\right)$ ou em água destilada.

Após uma hora, os pecíolos das folhas já secadas foram inseridos em um círculo de espuma, com $7 \mathrm{~cm}$ de diâmetro, acondicionado no fundo de um recipiente de plástico transparente $(500 \mathrm{~mL})$. A espuma foi umedecida com água destilada para manter a turgescência da folha até o final do experimento. Para cada folha tratada, foram transferidas cinco fêmeas ápteras de M. persicae. Posteriormente, outro recipiente de plástico transparente $(500 \mathrm{~mL})$, cujo fundo havia sido removido, foi colocado em posição invertida sobre o primeiro recipiente. As bordas dos dois recipientes foram mantidas juntas por meio de fita-crepe. A parte superior do recipiente invertido foi vedada com organza, presa por uma goma-elástica.

Os potes contendo as folhas com os pulgões foram mantidos em câmara climatizada a $25 \pm 2^{\circ} \mathrm{C}, 70 \pm 10 \%$ de umidade relativa do ar e fotófase de 14 horas. $\mathrm{O}$ delineamento experimental adotado foi o inteiramente casualizado, com nove repetições. Cada repetição foi representada por uma folha de pimenteira com cinco fêmeas de $M$. persicae. Após seis dias, avaliaram-se a mortalidade dos adultos, o número total de ninfas produzido pelas fêmeas e a mortalidade das ninfas em cada folha.

A homogeneidade das variâncias dos dados obtidos foi testada utilizando-se o teste de Bartlett (Sokal \& Rohlf, 1995). Os dados referentes à porcentagem de adultos e de ninfas mortos foram normalizados pela transformação $\mathrm{x}^{0,5}$. Todos os dados foram submetidos à análise de variância $\mathrm{e}$ as médias foram comparadas pelo teste de Tukey, a 5\% de probabilidade. Na realização das análises estatísticas, utilizou-se o programa Statistica versão 7.0. 
Afim de avaliar conjuntamente os efeitos dos produtos sobre a sobrevivência e a reprodução de $M$. persicae, calculou-se a taxa instantânea de crescimento populacional dos pulgões $\left(r_{i}\right)$, em cada tratamento, por meio da equação (Stark et al., 1997):

$\mathrm{r}_{\mathrm{i}}=\left[\ln \left(\mathrm{N}_{\mathrm{f}} / \mathrm{N}_{0}\right)\right] / \Delta \mathrm{t}$, em que $\mathrm{N}_{0}$ é o número inicial de indivíduos e $\mathrm{N}_{\mathrm{f}}$ é o número final de indivíduos na população no final do intervalo de tempo $\Delta \mathrm{t}(\mathrm{t}=6$ dias $)$. Valores positivos de $r_{i}$ significam que a população está em crescimento; $r_{i}=0$, que a população está em equilíbrio; valores negativos de $\mathrm{r}_{\mathrm{i}}$ indicam que a população está em declínio (Walthall \& Stark, 1997; Stark \& Banks, 2003).

$\mathrm{Na}$ avaliação do efeito do nim sobre E. connexa, larvas dessa espécie foram obtidas de uma criação mantida no laboratório de entomologia da Epamig/ CTZM. Essa criação era formada com insetos oriundos de plantios de pimenteira e de tomateiro da Zona da Mata de Minas Gerais. Na criação, adultos e larvas do predador foram alimentados com diversas espécies de pulgões. Plantas de pimenteira (altura média de $7 \mathrm{~cm}$ ), acondicionadas em vasos com capacidade de $3 \mathrm{~L}$ de substrato, foram infestadas com uma população de cerca de 150 pulgões ápteros (M. persicae) por planta. Após 24 horas da infestação, as plantas receberam aplicação de solução aquosa de extrato de semente de nim a $0,25 \%$ $\left(0,025 \mathrm{~g} \mathrm{~L}^{-1}\right.$ de i.a. $)$, a $0,5 \%\left(0,05 \mathrm{~g} \mathrm{~L}^{-1}\right.$ de i.a. $)$, de solução aquosa de acefato $\left(0,75 \mathrm{~g} \mathrm{~L}^{-1}\right.$ de i.a.) (Orthene 750 BR) e água destilada. A concentração de $0,5 \%$ foi utilizada porque causou efeito tóxico letal e subletal sobre M. persicae e não diferiu da concentração maior testada (1\%) (Tabela 1); a concentração de $0,25 \%$ foi utilizada para testar se uma concentração menor do produto teria também efeito nocivo ao predador.

Duas horas após a aplicação dos tratamentos, colocou-se uma larva de quarto ínstar de E. connexa por planta. Em seguida, para impedir a fuga das larvas, as plantas foram protegidas por tubos de plástico transparentes, sendo a extremidade superior vedada com voile preso por goma-elástica, e a extremidade inferior inserida no solo do vaso. Após 48 horas, as larvas foram transferidas das plantas para tubos de plástico $(7 \mathrm{~cm}$ de altura x $2,5 \mathrm{~cm}$ de diâmetro) e alimentadas com $M$. persicae até a formação da pupa.

Os tubos foram mantidos em câmara climatizada a $25 \pm 2^{\circ} \mathrm{C}, 70 \pm 10 \%$ de umidade relativa do ar e fotófase de 14 horas. O delineamento experimental adotado foi o inteiramente casualizado, com nove repetições. Cada repetição foi representada por uma planta de pimenteira contendo uma larva de E. connexa. A primeira avaliação foi realizada 5 horas após a aplicação das soluções ou da água destilada, sendo as demais feitas a cada 24 horas, por um período de 10 dias. Avaliaram-se a sobrevivência das larvas, a viabilidade da fase pupal e a porcentagem de adultos emergidos. Na realização das análises estatísticas, utilizou-se o mesmo método descrito para o experimento com M. persicae.

\section{Resultados e Discussão}

A porcentagem de mortalidade de adultos de M. persicae foi significativamente superior em folhas tratadas com o extrato de semente de nim, a 0,5 e $1 \%$, e com o acefato do que em folhas tratadas com água (Tabela 1).

Não houve produção de ninfas em folhas tratadas com acefato, possivelmente devido ao rápido efeito letal do produto sobre os adultos (Tabela 1). Os tratamentos de extrato de semente de nim não influenciaram na reprodução de $M$. persicae. No entanto, a porcentagem de ninfas mortas foi significativamente maior nas duas concentrações de nim, do que em água $(\mathrm{p}<0,05)$.

Tabela 1. População inicial, porcentagem de mortalidade de adultos, total de ninfas por planta, porcentagem de mortalidade de ninfas, população final e taxa instantânea de crescimento populacional de Myzus persicae em folhas de pimenteira tratadas com extrato de semente de nim, acefato e água. Temperatura de $25 \pm 2^{\circ} \mathrm{C}, 70 \pm 10 \%$ de umidade relativa e fotófase de 14 horas ${ }^{(1)}$.

\begin{tabular}{|c|c|c|c|c|c|c|}
\hline Tratamentos & $\begin{array}{l}\text { População } \\
\text { inicial }^{(2)}\end{array}$ & $\begin{array}{l}\text { Mortalidade de } \\
\text { adultos (\%) }\end{array}$ & $\begin{array}{l}\text { Total de ninfas } \\
\text { por planta }\end{array}$ & $\begin{array}{l}\text { Mortalidade de } \\
\text { ninfas }(\%)\end{array}$ & $\begin{array}{l}\text { População } \\
\text { final }^{(3)}\end{array}$ & $\begin{array}{c}\text { Taxa instantânea de crescimento } \\
\text { populacional }\left(\mathrm{r}_{\mathrm{i}}\right)\end{array}$ \\
\hline Nim $0,5 \%$ & 5 & $55,0 \pm 28,72 b$ & $42,4 \pm 23,09 a$ & $79,4 \pm 23,09 a$ & $13,3 \pm 23,09 b$ & $0,10 \pm 0,17 \mathrm{~b}$ \\
\hline $\operatorname{Nim} 1,0 \%$ & 5 & $59,1 \pm 34,75 b$ & $39,9 \pm 16,0 \mathrm{a}$ & $82,6 \pm 16,03 a$ & $9,9 \pm 16,03 b$ & $0,12 \pm 0,09 b$ \\
\hline Acefato & 5 & $96,9 \pm 8,84 b$ & $0,0 \pm 0,0 \mathrm{~b}$ & - & $0,1 \pm 0,00 \mathrm{~b}$ & - \\
\hline Água & 5 & $20,0 \pm 26,46 a$ & $49,7 \pm 23,33 a$ & $11,6 \pm 33,18 b$ & $52,8 \pm 25,52 a$ & $0,33 \pm 0,23 \mathrm{a}$ \\
\hline
\end{tabular}

${ }^{(1)}$ Médias \pm desvio-padrão seguidas de mesma letra, nas colunas, não diferem entre si pelo teste de Tukey, a 5\% de probabilidade. ${ }^{(2)}$ Número de fêmeas de $M$. persicae por planta antes da aplicação dos tratamentos. ${ }^{(3)}$ Número de adultos e ninfas de $M$. persicae vivos por planta, após 6 dias da aplicação dos tratamentos. 
Considerando-se o número final de adultos e ninfas de M. persicae por folha tratada após seis dias da aplicação dos tratamentos, verificaram-se diferenças significativas na população final de pulgões. Folhas tratadas com nim e com acefato apresentaram menor população de pulgões do que folhas tratadas com água.

Quando os efeitos letais e subletais foram analisados em conjunto, por meio da taxa instantânea de crescimento populacional $\left(\mathrm{r}_{\mathrm{i}}\right)$, verificou-se diferença significativa para pulgões de folhas tratadas com nim e de folhas tratadas com água. Não foi possível o cálculo da $r_{i}$ para pulgões em folhas tratadas com acefato em virtude da sobrevivência de apenas um pulgão, em uma repetição. Não houve diferença na taxa instantânea de crescimento populacional $\left(\mathrm{r}_{\mathrm{i}}\right)$ de $M$. persicae entre as duas dosagens do extrato de semente de nim. Ambas foram positivas, indicando que as populações de M. persicae presentes nessas folhas tendem a crescer. Porém, mostraram-se significativamente inferiores à taxa de crescimento da população oriunda de folhas de pimenteira tratadas com água $(\mathrm{p}<0,05)$.

Em condições de campo, a utilização de nim deve ser acompanhada por amostragens periódicas, sendo necessárias, possivelmente, pulverizações adicionais a fim de reduzir a população de pulgões, caso a população remanescente da primeira aplicação aumente. Estudos em campo com diversas espécies de pulgões em outras culturas evidenciam a necessidade de aplicações adicionais de produtos à base de nim para garantir a manutenção da população de pulgões abaixo do nível de dano que cause prejuízo econômico (Lowery et al., 1993; Partridge \& Borden, 1997).

Quanto ao predador E. connexa, verificou-se diferença significativa para a mortalidade de larvas de quarto ínstar expostas a plantas infestadas com M. persicae e tratadas com extrato de semente de nim, com acefato ou com água (Tabela 2). A porcentagem de larvas mortas foi maior em plantas tratadas com acefato do que nos demais tratamentos. No entanto, larvas do predador presentes em plantas tratadas com o extrato de semente de nim, nas duas concentrações testadas, tiveram mortalidade significativamente superior do que em plantas tratadas com água.

Com relação às pupas, os tratamentos com nim afetaram significativamente a viabilidade pupal do predador. Nas duas dosagens de nim, a viabilidade pupal foi significativamente inferior à obtida em indivíduos expostos a plantas tratadas com água $(\mathrm{p}<0,05)$, não tendo sido observado, nem mesmo, emergência de adultos provenientes de pupas originadas de larvas expostas aos tratamentos com nim.

Esses resultados evidenciam o efeito prejudicial do nim sobre essa espécie de predador (E. connexa) associado a pulgões em diversos agroecossitemas (Grützmacher \& Link, 2000; Sarmento, 2003; Oliveira et al., 2004). É necessário ressaltar, no entanto, que os resultados foram obtidos em laboratório, em arenas onde a mobilidade dos predadores foi limitada e não houve possibilidade de escape para áreas livres do produto. No campo, devido à alta mobilidade das larvas de E. connexa e à existência de refúgios, possivelmente, os efeitos do nim sejam minimizados.

Ressalta-se, também, que, no caso do controle químico convencional, a utilização contínua de determinados princípios ativos tem levado as populações de $M$. persicae ao desenvolvimento de resistência (Devonshire et al., 1998; Nauen \& Elbert, 2003). Quanto ao nim, devido aos diversos modos de ação da azadiractina e à presença de outros compostos ativos nos produtos formulados, o desenvolvimento de resistência por parte das pragas é minimizado (Ascher, 1993; Feng \& Isman, 1995). Há de se considerar, no entanto, os efeitos nocivos do nim sobre E. connexa. Segundo Ahmad et al. (2003), a manutenção de pequenas populações de pulgões, por meio de aplicações de produtos à base de nim em infestações iniciais, previne a atração de coccinelídeos para os focos de pulgões, o que contribui para minimizar os efeitos do nim sobre esses predadores. Portanto, apesar do potencial apresentado pelo nim, experimentos em campo são necessários para avaliar o impacto final do nim sobre as populações de pulgões e de seus inimigos naturais na cultura da pimenteira.

Tabela 2. Porcentagem de mortalidade larval, porcentagem de viabilidade pupal e porcentagem de emergência de adultos de Eriopis connexa em plantas de pimenteira infestadas com Myzus persicae e tratadas com extrato de semente de nim, acefato e água. Temperatura de $25 \pm 2^{\circ} \mathrm{C}, 70 \pm 10 \%$ de umidade relativa e fotófase de 14 horas $^{(1)}$.

\begin{tabular}{lccc}
\hline Tratamentos & $\begin{array}{c}\text { Mortalidade } \\
\text { larval (\%) }\end{array}$ & $\begin{array}{c}\text { Viabilidade } \\
\text { pupal (\%) }\end{array}$ & $\begin{array}{c}\text { Emergência de } \\
\text { adultos (\%) }\end{array}$ \\
\hline Nim 0,25\% & $54,5 \pm 52,22 \mathrm{~b}$ & $9,1 \pm 30,15 \mathrm{~b}$ & $0,0 \pm 0,00 \mathrm{~b}$ \\
Nim $0,50 \%$ & $30,0 \pm 48,3 \mathrm{~b}$ & $10 \pm 31,62 \mathrm{~b}$ & $0,0 \pm 0,00 \mathrm{~b}$ \\
Acefato & $100 \pm 0,00 \mathrm{a}$ & - & - \\
Água & $0,0 \pm 0,00 \mathrm{c}$ & $100 \pm 0,00 \mathrm{a}$ & $87,5 \pm 35,35 \mathrm{a}$ \\
\hline
\end{tabular}

${ }^{(1)}$ Médias \pm desvio-padrão seguidas de mesma letra, nas colunas, não diferem entre si pelo teste de Tukey, a 5\% de probabilidade. 


\section{Conclusões}

1. O extrato de semente de nim, nas concentrações de 0,05 e $0,1 \mathrm{~g}$ de azadiractina por litro, diminui o crescimento populacional de Myzus persicae em laboratório.

2. O extrato de semente de nim, nas concentrações de 0,025 e $0,05 \mathrm{~g}$ de azadiractina por litro, apresenta efeitos letais e subletais sobre o predador Eriopis connexa em laboratório.

\section{Agradecimentos}

Ao Dr. Hubertus Kleeberg, pelo fornecimento do produto NeemAzal T/S; à Dra. Regina Célia Zonta de Carvalho, do Centro de Diagnóstico Marcos Enrietti/ $\mathrm{SEAB}$, pela identificação do pulgão; ao $\mathrm{CNPq}$, pelo financiamento do projeto e pela concessão das bolsas.

\section{Referências}

AHMAD, M.; OBIEWATSCH, H.R.; BASEDOW, T. Effects of neem-treated aphids as food/hosts on their predators and parasitoids. Journal of Applied Entomology, v.127, p.458-464, 2003.

AKOL, A.M.; SITHANANTHAM, S.; NJAGI, P.G.N.; VARELA, A.; MUEKE, J.M. Relative safety of sprays of two neem insecticides to Diadegma mollipla (Holmgren), a parasitoid of the diamondback moth: effects on adult longevity and foraging behavior. Crop Protection, v.21, p.853-859, 2002.

ASCHER, K.R.S. Nonconventional insecticidal effects of pesticides available from the neem tree, Azadirachta indica. Archives of Insect Biochemistry and Physiology, v.22, p.433-449, 1993.

BLACKMAN, R.L.; EASTOP, V.F. Aphids on the world's crops: an identification guide. Chichester: J. Wiley, 1984. 466p.

DEVONSHIRE, A.L.; FIELD, L.M.; FOSTER, S.P.; MOORES, G.D.; WILLIAMSON, M.S.; BLACKMAN, R.L. The evolution of insecticide resistance in the peach-potato aphid, Myzus persicae. Philosophical Transactions of the Royal Society of London, v.353, p.1677-1684, 1998.

FENG, R.; ISMAN, M.B. Selection for resistance to azadirachtin in the green peach aphid Myzus persicae. Experientia, v.51, p.831833, 1995.

FRANÇA, F.H.; BARBOSA, S.; ÁVILA, A.C. Pragas do pimentão e da pimenta: característica e métodos de controle. Informe Agropecuário, v.10, p.61-67, 1984.

GRÜTZMACHER, A.D.; LINK, D. Survey of the entomofauna associated with potato varieties during two crop seasons. Pesquisa Agropecuária Brasileira, v.35, p.653-659, 2000.

ISMAN, M.B. Botanical insecticides, deterrents, and repellents in modern agriculture and an increasingly regulated world. Annual Review of Entomology, v.51, p.45-66, 2006.

LOWERY, D.T.; ISMAN, M.B.; BRARD, N.L. Laboratory and field evaluation of neem for the control of aphids (Homoptera: Aphididae). Journal of Economic Entomology, v.86, p.864-870, 1993.
MARTINEZ, S.S.; EMDEN, H.F. van. Growth disruption, abnormalities and mortality of Spodoptera littoralis (Boisduval) (Lepidoptera: Noctuidae) caused by Azadirachtin. Neotropical Entomology, v.30, p.113-124, 2001.

MINKS, A.K.; HARREWIJN, P. Aphids: their biology, natural enemies, and control. New York: Elsevier, 1987. 450p.

MORDUE, A.J.; NISBET, A.J. Azadirachtin from the neem tree Azadirachata indica: its action against insects. Anais da Sociedade Entomológica do Brasil, v.29, p.615-632, 2000.

NAUEN, R.; ELBERT, A. European monitoring of resistance to insecticides in Myzus persicae and Aphis gossypii (Hemiptera: Aphididae) with special reference to imidacloprid. Bulletin of the Entomological Research, v.93, p.47-54, 2003.

OLIVEIRA, N.C.; WILCKEN, C.F.; MATOS, C.A.O. Biological cycle and predation of three coccinellid species (Coleoptera, Coccinellidae) on giant conifer aphid Cinara atlantica (Wilson) (Hemiptera, Aphididae). Revista Brasileira de Entomologia, v.48, p.529-533, 2004.

PARTRIDGE, M.J.; BORDEN, J.H. Evaluation of neem seed extract for control of the spruce aphid, Elatobium abietinum (Walker) (Homoptera: Aphididae). Canadian Entomologist, v.129, p.899905, 1997.

PINTO, C.M.F.; SALGADO, L.T.; LIMA, P.C.; PICANÇO, M.; PAULA JUNIOR, T.J.P.; MOURA, W.M.; BROMMONSCHENKEL, S.H. A cultura da pimenta (Capsicum sp.). Belo Horizonte: Epamig, 1999. 40p. (Epamig. Boletim técnico, 56).

QUIROZ, C.; LARRAÍN, P.; SEPÚlVEDA, P. Abundancia estacional de insectos vectores de virosis en dos ecosistemas de pimiento (Capsicum annum L.) de la Región de Coquimbo, Chile. Agricultura Técnica, v.65, p.3-19, 2005.

SARMENTO, R.A. Resposta comportamental de artrópodes em teia alimentar de tomateiro. 2003. 61p. Dissertação (Mestrado) Universidade Federal de Viçosa, Viçosa.

SCHMUTTERER, H. Properties and potential of natural pesticides from neem tree. Annual Review of Entomology, v.35, p.271-297, 1990.

SCHMUTTERER, H. Side effects of neem (Azadirachata indica) products on insect pathogens and natural enemies of spider mites and insects. Journal of Applied Entomology, v.121, p.121-128, 1997.

SOKAL, R.R.; ROHLF, F.J. Biometry: the principles and practice of statistics in biological research. $3^{\text {rd }}$ ed. New York: W. H. Freeman, 1995. 887p.

STARK, J.D.; BANKS, J.E. Population-level effects of pesticides and other toxicants on arthropods. Annual Review of Entomology, v.48, p.505-519, 2003.

STARK, J.D.; TANIGOSHI, L.; BOUNFOUR, M.; ANTONELLI, A. Reproductive potential: its influence on the susceptibility of a species to pesticides. Ecotoxicology and Environmental Safety, v.37, p.273-279, 1997.

WALTHALL, W.K.; STARK, J.D. Comparison of two populationlevel ecotoxicological endpoints: the intrinsic $\left(\mathrm{r}_{\mathrm{m}}\right)$ and instantaneous $\left(r_{i}\right)$ rates of increase. Environmental Toxicology and Chemistry, v.16, p.1068-1073, 1997. 